\title{
DIREITO À INFORMAÇÃO QUALIFICADA NA RELAÇÃO MÉDICO- PACIENTE: ESTUDO DAS IMPLICAÇÕES DA DIFERENÇA ENTRE CERTIFICADO de Pós-Graduação lato Sensu e Título de Especialista em DERMATOLOGIA
}

\author{
RIGHT TO SPECIAL INFORMATION IN THE DOCTOR-PATIENT \\ RELATIONSHIP: STUDY OF THE IMPLICATIONS OF THE DIFFERENCE BETWEEN TWO \\ SPECIFIC CERTIFICATES IN DERMATOLOGY IN BRAZIL
}

Roberto Henrique Pôrto Nogueira ${ }^{1}$ Michael Cesar Silva ${ }^{2}$

\section{Resumo}

O trabalho aborda a pluralidade de certificados de formação técnica complementar médica dermatológica no Brasil e a necessidade de investigar a existência de eventual diferença significativa entre as mesmas. $\mathrm{O}$ embate acontece, principalmente, entre dois certificados, quais sejam, o de Pós-Graduação Lato Sensu em Dermatologia e o Título de Especialista em Dermatologia. Constatada a divergência, destacou a importância da formação técnica no processo de ponderação de variáveis técnicas ao paciente, que antecede a concessão do consentimento, concluindo por um direito do paciente à obtenção dessa informação qualificada, como resultado do preenchimento do conteúdo normativo do princípio da boa-fé objetiva.

Palavras-chave: Título de Especialista; Dermatologia; Informação qualificada; Boa-fé objetiva.

\footnotetext{
1 Doutorando e mestre em Direito Privado pelo Programa de Pós-Graduação da Pontifícia Universidade Católica de Minas Gerais. Especialista em Direito Tributário pela Faculdade de Direito Milton Campos. Graduado em Direito pela Pontifícia Universidade Católica de Minas Gerais. Professor Efetivo em Dedicação Exclusiva e Membro do Colegiado do Curso de Direito da Universidade Federal de Ouro Preto. Experiência profissional docente junto à Faculdade Mineira de Direito da Pontifícia Universidade Católica de Minas Gerais (Coração Eucarístico, Barreiro e São Gabriel), Faculdade Pitágoras e Faculdade Inforium de Tecnologia.Foi responsável pelo Núcleo de Prática Jurídica do Curso de Direito da Faculdade Pitágoras de Belo Horizonte. Destacam-se os seguintes campos de atuação: Direito Empresarial e Direito Civil. Temas de estudo: Teoria da Empresa, Direito dos Contratos, Direito de Informátca, Responsabilidade Civil e prática em Processo Civil, em supervisão de estágio.

2 Doutorando e Mestre em Direito Privado pela Pontifícia Universidade Católica de Minas Gerais. Especialista em Direito de Empresa pelo Instituto de Educação Continuada (IEC) da Pontifícia Universidade Católica de Minas Gerais. Graduação em Direito pela Pontifícia Universidade Católica de Minas Gerais. Possui experiência profissional na docência junto a Pós-graduação lato sensu (especialização) da Fundação Getulio Vargas - FGV DIREITO RIO, a Pós-graduação do Instituto Nacional de Medicina Legal de Portugal, I.P., a Pós-graduação lato sensu (nível especialização) do Departamento de Odontologia da Pontifícia Universidade Católica de Minas Gerais (Campus Coração Eucarístico), a Faculdade Mineira de Direito da Pontifícia Universidade Católica de Minas Gerais (Campus Coração Eucarístico e São Gabriel), ao Centro Universitário Newton Paiva e a Faculdade de Direito Promove. Participação em projetos e atividades acadêmicas relacionadas a realização e/ou coordenação de seminários, mini-cursos, palestras, orientação de pesquisa e de monografia de final de curso. Editor de Revista Jurídica. Membro de Conselho Editoral. Membro da Associação Mineira de Direito e Economia (AMDE). Advogado. Experiência profissional e atuação nas seguintes áreas: Direito Empresarial, Direito Civil, Direito do Consumidor e Direito Securitário.
}

Revista da Faculdade Mineira de Direito, v.14, n. 27, jan./jun. 2011 - ISSN 1808-9429. 


\section{CONSIDERAÇÕES INICIAIS}

O atual panorama social sinaliza para novos direitos, impostos pelo sistema jurídico, na medida em que surgem celeumas antes inexistentes.

A evolução da medicina e a proliferação dos cursos de Pós-Graduação Lato Sensu em todo o país deflagram um problema, qual seja, a eventual existência de diferença na formação técnica do médico, conforme tenha realizado Residência Médica, Especialização ou PósGraduação Lato Sensu em determinada área de conhecimento da medicina.

$\mathrm{O}$ trabalho revela-se de extrema relevância à comunidade como um todo, haja vista que, com freqüência, os termos de consentimento informado que são entregues aos pacientes por seus médicos sucedem prévia explicação verbal que, muitas vezes, pauta-se em argumento de autoridade, envolto a uma série de variáveis técnico-científicas impassíveis de compreensão pelo leigo.

Significa dizer que, a despeito da tentativa do profissional ético em inteirar o paciente e a família das implicações de uma intervenção terapêutica, certamente que a ponderação do médico sobre os prognósticos, terapêutica, complicações e utilidade de um determinado procedimento é decisivo para a concessão de um consentimento pré-estabelecido e redigido unilateralmente.

Não se tratará do consentimento propriamente dito, pois esta seria uma outra empreitada tão desafiadora quanto a da análise do processo que o antecede. Mesmo porque são recorrentes os trabalhos que enfrentam a validade do consentimento informado dado pelo paciente ao médico, diante da necessidade de tratamento específico.

Assim, tão importante quanto a tentativa de promover a compreensão mínima sobre aspectos técnico-científicos na relação médico-paciente, é garantir ao paciente ou a sua família o direito de averiguar a legitimidade do profissional médico na condução do processo decisório que antecede o consentimento para a realização de intervenção terapêutica, por meio da prestação de informações qualificadas sobre a perícia profissional, que muito depende da formação técnica.

Assim, resta investigar se a dita diferença entre formações técnicas de nomes diversos existe e, caso afirmativo, se é possível exigir do médico o dever positivo de fornecer ao paciente informações sobre a sua formação técnico-científica, para garantia da legitimidade de sua condução do processo de formação da convicção do paciente ou de sua família para o consentimento. 
A esta altura, e tendo em vista a complexidade do sistema jurídico da atualidade, desponta como imperativa a definição do microssistema que servirá de pano de fundo pano de fundo para a superação das celeumas apontadas.

Em primeiro impulso, invocaria-se o Direito do Consumidor, diante da verdadeira relação de consumo que se constitui a relação médico-paciente.

Mas assim seria, necessariamente, imperioso o tratamento dos objetivos, princípios e direitos básicos do Direito do Consumidor, dos elementos subjetivo, objetivo, e teleológico para a configuração da relação de consumo, da responsabilidade civil, penal e administrativa do fornecedor, da proteção contratual do consumidor, da defesa do consumidor em juízo. Ademais, o artigo não busca discutir políticas públicas de proteção ao consumidor vulnerável, o que poderia resultar na perda do foco no objetivo central.

A expectativa é de viabilizar a superação do problema por um caminho que não se restrinja a um microssistema jurídico específico ou se justifique a partir da constatação de uma relação não paritária é a razão da proposta de averiguação da existência desse direito do paciente com fundamento no conteúdo deôntico do princípio da boa-fé objetiva.

Interessa, particularmente, o teste da hipótese, qual seja, o reconhecimento do direito do paciente de obter do profissional a explicação sobre o processo de sua formação, haja vista que este é elemento fundamental para o reconhecimento da legitimidade do médico na atividade de ponderação dos programas de prevenção, diagnóstico, terapêutica principal e de complicações, para a posterior concessão do consentimento.

Ao final, caso o estudo aponte para a efetividade da existência de diferença objetiva na formação técnica de médicos dermatologistas, conforme tenham obtido formação via PósGraduação Lato Sensu, Residência Médica ou Especialização, será possível delinear uma nova roupagem do direito à informação qualificada do paciente em relação ao médico.

Para tratamento profícuo dessa diferença, é útil, metodologicamente, o recorte do trabalho a uma área específica de atuação médica. Tomou-se por referência a Dermatologia no Brasil.

A operacionalização do trabalho acontecerá essencialmente por meio de procedimentos de coleta de dados em fonte bibliográfica e legal, para elucidar as noções de Pós-Graduação Lato Sensu, Residência Médica e Especialização em Dermatologia. Em privilégio do raciocínio dedutivo, se as exigências normativas forem significativamente diferentes para a certificação desses meios de formação profissional, estará estabelecida a premissa da relevância do conhecimento da diferença pelo paciente. Então, restará o estudo do 
princípio da boa-fé objetiva, de maneira que, em conclusão, seja alcançado o eventual reconhecimento do direito á informação qualificada.

\section{DEFINIÇÃO DO PROBLEMA}

É proposto responder se o Certificado de Pós-Graduação Lato Sensu, de acordo com a Resolução CES/CNE nº 01 (BRASIL, 2001; BRASIL, 2007), pode ser ou é considerado como Título de Especialização em Dermatologia, ou seja, se o Certificado de Pós-Graduação Lato Sensu em Dermatologia é suficiente para que alguém se declare especialista em dermatologia.

No mesmo sentido, é imperioso investigar o que deve ser entendido por Título de especialista em Dermatologia.

Dessa maneira, a controvérsia diz respeito às semelhanças e/ou diferenças havidas entre o Título de Especialista, que pode ser conferido a profissionais médicos, e o Certificado de Pós-Graduação Lato Sensu.

\section{VARIÁVEIS DE TRATAMENTO NECESSÁRIO}

Para uma conclusão coerente acerca da controvérsia apresentada, é essencial verificar a competência para emitir e validar tais documentos, o fundamento de validade dos documentos referenciados, seus regimes jurídicos e requisitos de concessão, além de seus objetivos. Ao final, restará verificar, dentro dos objetivos explicitados, se o conteúdo deôntico do princípio da boa-fé objetiva autoriza a afirmação da existência, no Direito brasileiro, do direito do paciente a uma prestação positiva por parte do médico, de informar acerca de sua formação técnica, para reconhecimento da legitimidade do profissional para atuar na condução do processo de ponderação de variáveis científicas que antecedem o consentimento.

\section{FUNDAMENTAÇÃO}

\subsection{Pós-Graduação Lato Sensu}

O órgão federal competente para regulamentar a Pós-Graduação Lato Sensu no Brasil é o MEC, Ministério da Educação.

Conforme a Resolução CNE/CES n 1 (BRASIL, 2007), que estabelece normas para o funcionamento de cursos de Pós-Graduação, em nível de especialização, o Presidente da Câmara de Educação Superior do Conselho Nacional de Educação, no uso de suas atribuições legais, tendo em vista o disposto nos arts. $9^{\circ}$, inciso VII, e 44, inciso III, da Lei ${ }^{\circ} 9.394$, de 20 de dezembro de 1996, e com fundamento no Parecer CNE/CES n 263/2006, homologado por

Revista da Faculdade Mineira de Direito, v.14, n. 27, jan./jun. 2011 - ISSN 1808-9429. 74 
Despacho do Senhor Ministro da Educação em 18 de maio de 2007, publicado no DOU de 21 de maio de 2007, resolveu que qualquer instituição de ensino superior - IES devidamente credenciadas pode oferecer cursos de Pós-Graduação Lato Sensu, independentemente de autorização, reconhecimento ou renovação de reconhecimento. Devem, para tanto, atender o disposto na referida resolução.

O artigo $5^{\circ}$ da mesma resolução faz previsão de que os cursos de Pós-Graduação Lato Sensu, em nível de especialização, têm duração mínima de 360 (trezentas e sessenta) horas, nestas não computado o tempo de estudo individual ou em grupo, sem assistência docente, e o reservado, obrigatoriamente, para elaboração individual de monografia ou trabalho de conclusão de curso.

Ademais, os referidos cursos de Pós-Graduação Lato Sensu podem, ainda, ser oferecidos à distância, desde que oferecidos por instituições de ensino superior legalmente autorizadas e que incluam provas presenciais e defesa presencial individual de monografia ou trabalho de conclusão de curso.

O Certificado de conclusão do curso é expedido, diretamente, pela instituição responsável pelo curso de Pós-Graduação Lato Sensu.

Para os fins aos quais os mesmos se direcionam, os Certificados de conclusão de cursos de Pós-Graduação Lato Sensu, que se enquadrem nos dispositivos estabelecidos na resolução, possuem validade nacional.

Insta frisar: atendidos os requisitos listados acima, os Certificados de Pós-Graduação Lato Sensu têm validade nacional. Significa que o título é hábil a provar a educação continuada, computar pontos em provas de títulos, em concursos públicos, além de, eventualmente, habilitar seu titular a ministrar aulas em cursos superiores.

Logo, os objetivos precípuos da Pós-Graduação Lato Sensu é a educação continuada. É a prova, portanto, da realização de estudos adicionais. Não possui, necessariamente, a pretensão de realização de treinamento em serviço. Trata-se de complementação de estudos, que se realiza conforme critérios estabelecidos pelas IES, que, por sua vez, podem estabelecêlos, autonomamente.

Significa dizer que as Sociedades de especialidades médicas, tal como a Sociedade Brasileira de Dermatologia, em princípio, parecem não participar da formação e controle da qualidade dos referidos cursos.

Insta pontuar, contudo, que a mesma Resolução CNE/CES nº 1 (BRASIL, 2007) dispõe que se excluem do âmbito de aplicabilidade do referido texto normativo os cursos de 
Pós-Graduação denominados de aperfeiçoamento e outros. Logo, atividades complementares de estudo e preparação profissional não são, todos, dotados do mesmo objetivo ou fundamento de validade. Pós-Graduação é gênero do qual Pós-Graduação Lato Sensu é espécie.

Diferencia-se, portanto, o Certificado de conclusão de curso de Pós-Graduação Lato Sensu do Título de Especialista, conforme exposto a seguir.

\subsection{Título de Especialista e Residência Médica}

Diante da relevância social da profissão médica, e de seu contato direito com a vida humana, o legislador ordinário desejou constituir um título que assegurasse à comunidade em geral a realização, pelo médico que se declara especialista, de treinamento rigoroso em serviço, dotado de regulamentação legal, além de acompanhamento pelas associações de especialidades, tudo no sentido de assegurar o melhor exercício da profissão.

Não se trata, somente, de educação continuada, mas de treinamento em serviço, efetivo, ou especialização equivalente, cuja concessão do título somente ocorre após a submissão, do médico, a detalhados procedimentos avaliativos de alto grau de exigência técnica, amplamente controlados e institucionalizados pelos órgãos competentes, conforme suas atribuições legais e estatutárias.

Entretanto, para a compreensão do Título de Especialista, é mister compreender o regime jurídico da Residência Médica no Brasil.

Inicialmente, o Decreto n. 80.281 (BRASIL, 1977) regulamentou a Residência Médica e criou a Comissão Nacional de Residência Médica. A Lei Federal n. ${ }^{\circ} 6.932$ (BRASIL, 1981) dispõe sobre as atividades do médico residente. Legalmente, a Residência Médica constitui modalidade de ensino de Pós-Graduação, destinada a médicos, sob a forma de cursos de especialização, caracterizada por treinamento em serviço, funcionando sob a responsabilidade de instituições de saúde, universitárias ou não, sob a orientação de profissionais médicos de elevada qualificação ética e profissional.

Diferente dos cursos de Pós-Graduação Lato Sensu (com duração total mínima de 360 - trezentos e sessenta - horas), os programas de Residência têm a duração anual mínima de 1800 (um mil e oitocentas) horas de atividade. No caso da Dermatologia, os programas, atualmente, possuem, ao todo, duração de 03 (três) anos.

Além do treinamento em serviço, os Programas de Residência Médica compreendem um mínimo de quatro horas semanais de atividades sob a forma de sessões de atualização, 
seminários, correlações clínico-patológicas ou outras, sempre com a participação ativa dos alunos.

Aos médicos que completam o programa de Residência em Medicina, com aproveitamento suficiente, é conferido o Certificado de Residência Médica, de acordo com as normas baixadas pela Comissão Nacional de Residência Médica.

Para que as instituições de saúde ofereçam programas de Residência Médica, devem, necessariamente, ser credenciadas pela Comissão Nacional de Residência Médica.

Assim, a lei veda o uso da expressão Residência Médica para designar qualquer programa de treinamento médico que não tenha sido aprovado pela Comissão Nacional de Residência Médica.

O rigor do treinamento em serviço, para a preparação do médico em determinada especialidade, inicia-se quando de sua admissão em qualquer curso de Residência Médica, haja vista que o candidato deve se submeter a processo de seleção estabelecido pelo programa aprovado pela Comissão Nacional de Residência Médica.

Com a pretensão de reconhecer especialidades médicas e de regulamentar a possibilidade de concessão de Títulos de Especialistas a outros médicos que se submetam a programas de treinamento em serviço tão criteriosos quanto a Residência Médica, o Conselho Federal de Medicina, no uso das atribuições que lhe confere a Lei $n^{\circ} 3.268$ (BRASIL, 1957), regulamentada pelo Decreto 44.045 (BRASIL, 1958), editou Resolução por meio da qual firmou o convênio de reconhecimento de especialidades médicas entre o Conselho Federal de Medicina CFM, a Associação Médica Brasileira - AMB e a Comissão Nacional de Residência Médica - CNRM.

As entidades mencionadas formam a Comissão Mista de Especialidades (CME). Este convênio tem por finalidade a conjugação de esforços dos convenentes para estabelecer critérios para o reconhecimento e denominação das especialidades médicas, além do modo de concessão e registro de Título de Especialista e Certificado de área de atuação médica.

Conforme a dita resolução, é vedada, ao médico, a divulgação de especialidade ou área de atuação que não seja reconhecida pelo Conselho Federal de Medicina ou pela Comissão Mista de Especialidades.

Logo, pelo convênio, o médico só pode declarar vinculação com especialidade ou área de atuação quando for possuidor do Título ou Certificado a ele correspondente, devidamente registrado no Conselho Regional de Medicina. 
À Comissão Nacional de Residência Médica - CNRM, coube credenciar e autorizar o funcionamento dos programas de residência médica. À Associação Médica Brasileira - AMB, coube orientar e fiscalizar a forma de concessão de títulos e certificados. Ao Conselho Federal de Medicina, por sua vez, foi reservada a atribuição para o registro de títulos e certificados.

Em conformidade com o convênio, as especialidades e áreas de atuação médica reconhecidas pelas entidades convenentes têm denominação uniforme e são obtidas por órgãos formadores acreditados, quais sejam, as residências médicas credenciadas e com funcionamento autorizado pela CNRM e as Sociedades de Especialidades filiadas à AMB, com programas de ensino por ela aprovados.

Os Títulos de Especialistas e os Certificados de área de atuação obtidos através da AMB deverão subordinar-se portanto, aos seguintes critérios:

a. Concurso realizado na Sociedade de Especialidade, desde que seja ela filiada à $\mathrm{AMB}$ e atenda aos requisitos aprovados pela Comissão Mista de Especialidades - CME;

b. O concurso referido deverá constar de, no mínimo, currículo e prova escrita e, se necessário, oral e/ou prática.

A Sociedade de Especialidade, ainda com base no mesmo convênio, pode definir os critérios para a concessão de Título de Especialista ou Certificado de área de atuação, desde que conhecidos e aprovados previamente pela Associação Médica Brasileira - AMB.

Tais concursos para concessão de Título de Especialista e Certificado de área de atuação são anuais.

A AMB emite apenas títulos e certificados que atendam às determinações da CME, sendo que, nos editais de concurso para Título de Especialista ou Certificado de área de atuação, a AMB deve observar o tempo mínimo de formação na especialidade ou área de atuação.

Assim, os Conselhos Regionais de Medicina (CRM) registram apenas Títulos de Especialidade e Certificados de áreas de atuação reconhecidos pela CME.

No caso da Dermatologia, a certificação, na AMB, ocorre via Sociedade de Especialidade, ou seja, por meio da Sociedade Brasileira de Dermatologia.

Por fim, a última edição consultada do mesmo convênio, reconhecida pela Resolução CFM No 1.845 (BRASIL, 2008), fixou, como pré-requisito para concessão do Título de especialista em Dermatologia, a exigência de formação mínima de 3 (três) anos, em Programa 
de Residência Médica em Dermatologia (CNRM) ou equivalente, assim reconhecido pela Sociedade Brasileira de Dermatologia.

Para a análise das exigências para a concessão do Título de Especialista, tomou-se por base o edital do XLIII Exame para obtenção do referido título, publicado pela Sociedade Brasileira de Dermatologia. Por meio da sua Comissão de Título de Especialista, tornou pública a realização do Exame para Obtenção do Título de Especialista em Dermatologia (TED), mediante condições estabelecidas no edital.

Para a inscrição, o candidato deveria, na data da consulta ao documento público:

a) estar inscrito no Conselho Regional de Medicina (CRM definitivo); b) ter concluído Residência Médica em Dermatologia, em Instituição credenciada pela Comissão Nacional de Residência Médica (CNRM) do MEC; ou --- ter concluído 2 (dois) anos de especialização ou estágio em Dermatologia, equivalente ao programa de Residência Médica da CNRM, em Serviço credenciado pela Sociedade Brasileira de Dermatologia(SBD) ${ }^{3}$, sendo que, neste caso, o candidato deve ter ocupado uma

3 Para verificação dos critérios de credenciamento dos cursos considerados como equivalentes à residência médica, ver Regimento para Credenciamento de Serviços, da Sociedade Brasileira de Dermatologia: Extratos: Compete à Comissão de Ensino: I - credenciar e descredenciar Serviços para Treinamento em Dermatologia, que cumpram programa definido pelo regimento da comissão e referendado pelo Conselho Deliberativo; REGULAMENTO PARA CREDENCIAMENTO DE SERVIÇOS: Os Serviços interessados no Credenciamento ou Recredenciamento de suas Residências Médicas ou Cursos de Especialização em Dermatologia pela SBD, deverão enviar solicitação juntamente com relatório próprio preenchido (Formulário para Credenciamento / Recredenciamento de Cursos de Residência Médica/Especialização em Dermatologia). A Comissão de Ensino designará uma Comissão Verificadora composta de no mínimo 2 (dois) de seus membros, para proceder à visita do Serviço visando posterior apreciação e votação do relatório de inspeção por toda a Comissão, nas Reuniões Ordinárias da Comissão de Ensino (art. 38 do Estatuto da SBD). Após aprovação da Comissão o relatório deverá ser encaminhado a SBD para que esta notifique o Serviço e proceda ao arquivamento do relatório. O julgamento da Comissão de Ensino deverá ser baseado nos critérios estabelecidos neste Regulamento para Credenciamento de Serviços: 1. SERVIÇO DE DERMATOLOGIA: a. Das obrigatoriedades: i. pertencer ou ter vínculo formal com um Hospital Geral, sendo aceito convênio reconhecido por ambas as partes e que garanta o cumprimento dos dispositivos deste regimento; ii. funcionar no mínimo 40 (quarenta) horas semanais. b. Das Recomendações: i. o hospital ao qual o Serviço esteja vinculado deverá ser geral e/ou universitário; ii. o hospital disponha no mínimo de 100 (cem) leitos; iii. o curso de especialização deve ser preferencialmente vinculado a uma instituição de ensino médico. 2. CORPO DOCENTE: a. Das obrigatoriedades: i. o coordenador do curso deve ter Título de Especialista da SBD e experiência docente em medicina; ii. todos os preceptores devem ter o Título de Especialista da SBD, exceto os colaboradores de outras áreas e especialidades médicas; iii. o número total mínimo de docentes portadores de título de especialista da SBD é 4 (quatro); iv. mínimo de 1 (um) preceptor para cada 2 (dois) residentes/especializandos. 3. AMBULATÓRIO: a. Das obrigatoriedades: i. funcionar todos os dias úteis com atendimento mínimo de 20 (vinte) horas semanais; ii. atender um mínimo de 40 (quarenta) consultas por semana, por residente/especializando, sendo no mínimo 20 (vinte) correspondentes a novas consultas; iii. supervisão docente do atendimento ambulatorial; b. Das recomendações: i. o número de consultórios deve ser compatível com o número de residentes ou equivalentes; ii. a setorização de ambulatórios por áreas específicas, com rodízio de residentes/especializandos, é recomendável, dependendo do volume de atendimento. 4. ENFERMARIA: a. Das obrigatoriedades: i. disponibilidade de leitos para internações de pacientes dermatológicos; ii. no mínimo 1 (uma) visita semanal com supervisão docente aos pacientes internados. b. Das recomendações: i. seja destinado ao Serviço no mínimo 1 (um) leito por residente/especializando; ii. mínimo de 12 (doze) internações por ano para cada residente/especializando; iii. prestação de interconsultas a pacientes de outras clínicas com intercorrências dermatológicas; 5. RECURSOS DIDÁTICOS E MATERIAIS: a. Das obrigatoriedades: i. ter à disposição do Serviço, em quantidade compatível com o número de residentes/especializandos, no mínimo, os seguintes equipamentos: 1.

Revista da Faculdade Mineira de Direito, v.14, n. 27, jan./jun. 2011 - ISSN 1808-9429. 
das vagas credenciadas pela SBD e assim, deverá constar na listagem enviada pelos serviços credenciados à SBD; ou --- ter realizado treinamento e ter atuação regular na dermatologia, durante pelo menos os últimos 5 (cinco) anos (a partir de 01 de abril de 2004) e possuir no mínimo 100 (cem) pontos resultantes da somatória dos itens constantes da tabela editalícia.

O exame para a concessão do Título de Especialista do concurso em apreço foi composto de 2 (duas) fases: prova teórica, com 80 (oitenta) questões objetivas, sendo exigido o mínimo de 48 (quarenta e oito) questões certas, ou seja, 60\% de acertos com correção pelo sistema de leitura óptica; e prova teórico-prática, realizada em computador constando de 30 (trinta) questões, sendo exigido o mínimo de 18 (dezoito) questões certas, ou seja, 60\% (sessenta por cento) de acertos.

Aos candidatos aprovados, nos moldes das previsões do edital, foi concedido o Título de Especialista em Dermatologia.

Diante do estabelecimento de novos critérios, para a inscrição no concurso de Título de Especialista, a partir de 2010 passaram a ser exigidos, dentre outros, os seguintes requisitos:

a) estar inscrito no Conselho Regional de Medicina (CRM definitivo); b) ter concluído 3 (três) anos de Residência Médica em Dermatologia, em Instituição credenciada pela Comissão Nacional de Residência Médica (CNRM) do MEC; ou--ter concluído 3 (três) anos de especialização ou estágio em Dermatologia, equivalente ao programa de Residência Médica da CNRM, em Serviço credenciado pela Sociedade Brasileira de Dermatologia (SBD), sendo que, neste caso, o candidato deverá ter ocupado uma das vagas credenciadas pela SBD e assim, deverá constar na listagem enviada pelos serviços credenciados à SBD; ou --- ter concluído

microscópio, 2. projetor de diapositivos, 3. retroprojetor, 4. câmera fotográfica, 5. dermatoscópio, 6. aparelhos de eletrocirurgia 7. equipamentos de criocirurgia; ii. manter arquivo de diapositivos dos casos de maior interesse; iii. disponibilizar no Serviço: 1. livros-texto de Dermatologia para consultas; 2. coleção de periódicos de dermatologia no serviço, no mínimo os Anais Brasileiros de Dermatologia; 3. sala de reunião e de leitura no serviço; iv. disponibilizar na Instituição: 1. biblioteca médica geral; 2. setor de micologia com laboratório; 3. setor de dermatopatologia; 4. sala equipada de cirurgia dermatológica. b. Das recomendações: i. disponibilizar no serviço: 1. arquivo de lâminas de dermatopatologia das biópsias realizadas no serviço; 2 . no mínimo todos os livros-texto de Dermatologia nacionais; 3. laboratório de micologia; 4. sala equipada de cirurgia dermatológica. 5. estimular o acesso a internet para permitir revisões bibliográficas 6. CARACTERÍSTICAS DO PROGRAMA: a. Das obrigatoriedades i. a duração mínima da residência/curso de especialização é de 2 (dois) anos, excluído o período de pré-requisito, quando exigido pela instituição; ii. o número de vagas disponíveis por ano deve estar na dependência do número de leitos em enfermaria, salas de ambulatório, recursos materiais e corpo docente; iii. o número de residentes/especializandos do Serviço corresponderá exclusivamente às vagas Credenciadas pela SBD; iv. estagiários serão admitidos desde que tenham o seu estágio restrito a 6 (seis) meses, prorrogável por mais seis, tendo seu estágio restrito a no máximo dois setores do Serviço. v. a carga anual mínima obrigatória é de 1920 (um mil, novecentos e vinte) horas, correspondendo a 40 (quarenta) horas semanais durante 48 (quarenta e oito) semanas (grifos nossos); vi. cursos formais teórico-práticos de micologia dermatológica, dermatopatologia e cirurgia dermatológica; vii.reuniões clínicas, seminários programados, clubes de revista e sessões iconográficas ou sessões equivalentes. viii. aprovação de no mínimo $50 \%$ (cinqüenta por cento) dos residentes/especializandos no período Credenciado para concessão de Recredenciamento). b. Das recomendações: i. uma sessão semanal de cada uma das propostas no item vii acima ii. os residentes/especializandos deverão em sua totalidade prestar o concurso de Título de Especialista da SBD.

Revista da Faculdade Mineira de Direito, v.14, n. 27, jan./jun. 2011 - ISSN 1808-9429. 
1 (um) ano de Residência Médica em clínica médica e 2 (dois) anos de especialização ou estágio em dermatologia com programa equivalente ao da Residência Médica em Dermatologia da CNRM (R2 e R3), em serviço credenciado pela Sociedade Brasileira de Dermatologia; ou--- ter realizado treinamento e ter atuação regular na dermatologia, durante pelo menos os últimos 6 (seis) anos contados da data da abertura da inscrição do Exame e possuir no mínimo 100 (cem) pontos resultantes da somatória dos itens constantes da tabela editalícia.

Dessa maneira, constatam-se diferenças objetivas que respeitam à duração dos programas de formação técnica, que, considera-se, são significativas, haja vista a carga horária bastante superior de um programa em relação ao outro, além dos diversos critérios para credenciamento de serviços. Ao que parece, e partindo de uma análise objetiva, os requisitos à concessão do Título de Especialista são mais numerosos, uniforme e publicamente estabelecidos, que tendem, ao menos, a favorecer um efetivo treinamento em serviço.

\subsection{Da diferença entre o Certificado de Pós-Graduação Lato Sensu em Dermatologia e do Título de Especialista em Dermatologia}

Títulos de Especialista, ao invés de título de especialização, são somente aqueles outorgados em conformidade com o convênio da Comissão Mista de Especialidades, que, após concurso, são concedidos aos aprovados, somente, e que atestam a realização de treinamento de, aproximadamente, 02 (dois) a 03 (três) anos em serviço.

Parece-nos ser título qualificado de educação continuada acompanhado pela Comissão Mista de Especialidades e, sobretudo, que atesta o desempenho satisfatório da atividade profissional supervisionada anterior, devidamente constatada por concurso promovido pela Sociedade Brasileira de Dermatologia.

Lado outro, como dito anteriormente, o Certificado de conclusão de Pós-Graduação Lato Sensu comprova a realização de curso com o objetivo de promover a educação continuada, sem a necessária pretensão de realização de treinamento em serviço. Trata-se de complementação de estudos, que se realiza conforme critérios estabelecidos pelas Instituições de Ensino Superior, que, por sua vez, podem estabelecê-los, autonomamente. Usualmente, tais cursos possuem carga horária mínima de 360 (trezentos e sessenta) horas. Os certificados, assim como os cursos, situam-se dentro da autonomia das IES, não se submetendo, por obrigação, a qualquer disposição da Comissão Mista de Especialidades, tampouco da Sociedade Brasileira de Dermatologia.

É forçoso concluir que, para a comprovação de realização de treinamento em serviço equivalente à Residência Médica e, ainda, para certificação de aprovação no concurso de

Revista da Faculdade Mineira de Direito, v.14, n. 27, jan./jun. 2011 - ISSN 1808-9429. 
Título de Especialista, o Certificado de conclusão de Pós-Graduação Lato Sensu não parece ser documento adequado. São certificados distintos, posto que reconhecem aperfeiçoamentos distintos. Dentro de seus objetivos peculiares e de suas fundamentações legais diversas e, sobretudo, considerando as peculiaridades estruturais de cada programa, ambos são válidos em todo o território nacional, para os fins aos quais se propõem.

O paciente, para que conceda seu consentimento efetivamente informado, deve ter a convicção da formação profissional do médico, na ponderação dos elementos científicos do diagnóstico, terapêutica e complicações. Afinal, a legitimidade no exercício de tal atividade de informação pode ser determinante da decisão de consentir.

Não é pretendida a realização de um juízo de valor. Em verdade, diante da validade de ambos, haverá, por certo, pacientes satisfeitos com ambas as formações técnicas. Mas para que o consentimento seja, efetivamente, informado, o paciente deve ter informações qualificadas, para que possa julgar a articulação dos fatos e projeções pelo profissional de saúde.

Logo, ao final da primeira fase do trabalho, tem lugar o estudo do princípio da boa-fé objetiva, para viabilizar o teste da hipótese em completude, de maneira que o trabalho possa posicionar-se pela eventual existência de direito do paciente a essa informação que aqui é chamada de qualificada.

\section{O PRINCÍPIO DA BOA-FÉ OBJETIVA}

\subsection{Lineamentos no ordenamento jurídico pátrio}

O princípio da boa-fé objetiva apresenta-se, na atualidade, como um dos mais importantes princípios do Direito Privado. Possui grande relevância no Direito Contratual, dada sua positivação expressa tanto no Código de Defesa do Consumidor (BRASIL, 1990) quanto no Código Civil (BRASIL, 2002).

A boa-fé objetiva foi esculpida, inicialmente, no Direito brasileiro, no artigo 131, I, do Código Comercial (BRASIL, 1950), no qual já se previa expressamente o referido princípio, de cunho contratual, no tocante ao aspecto interpretativo. No Código Civil anterior (BRASIL, 1916) havia tão somente a acepção subjetiva da boa-fé.

Posteriormente, a boa-fé objetiva foi inserida no Código de Defesa do Consumidor (BRASIL, 1990) (artigo $4^{\circ}$, III e 51, IV) e, já recentemente, no Código Civil vigente (BRASIL, 2002), através da previsão legal do art. 422, em consonância com os artigos 113 e 187.

Revista da Faculdade Mineira de Direito, v.14, n. 27, jan./jun. 2011 - ISSN 1808-9429. 
O princípio em comento ensejou profunda modificação na concepção tradicional de contrato (relação jurídica estática), que passa a ser visto como relação jurídica complexa e dinâmica (COUTO E SILVA, 1976, p.10-11) ${ }^{4}$, formado por um feixe de obrigações múltiplas e recíprocas. Nesse sentido, a autonomia privada é modelada, integrada, relativizada ou mesmo, para alguns, mitigada pela inserção da boa-fé objetiva nas relações jurídicas contratuais.

O princípio da boa-fé objetiva constitui-se regra de conduta, de comportamento ético, social imposta às partes, pautada nos ideais de honestidade, retidão e lealdade, no intuito de não frustrar a legítima confiança, expectativa da outra parte, tendo ainda, a finalidade de estabelecer o equilíbrio nas relações jurídicas (ROSENVALD, 2005, p.80) ${ }^{5}$.

Destarte, fundamenta-se na necessidade de as partes atuarem, reciprocamente, com cooperação, lealdade, honestidade e confiança (FIUZA, 2006, p. 410-411) ${ }^{6}$, no intuito de concretizar a diretriz da eticidade, preconizada no Código Civil.

Por fim, o princípio da boa-fé objetiva integra o negócio jurídico por meio dos chamados deveres anexos (proteção, cooperação e dever de informação, dentre outros), os quais visam a consagrar sua finalidade precípua, o adimplemento do contrato, devendo ser observados na fase pré-contratual, de execução do contrato e na fase pós-contratual.

Deste modo, a boa-fé objetiva é verdadeiro elemento transformador de todo o Direito Obrigacional, irradiando-se para os demais ramos do Direito, e em especial o Contratual (MARTINS-COSTA, 2002, p. 611). Esta se traduz como a concretização do princípio da dignidade no campo das obrigações, e, por conseguinte, no Direito Contratual (FARIAS; ROSENVALD, 2006, p.41). Trata-se de princípio a ser concretizado pelo intérprete de acordo com as circunstâncias do caso concreto.

\subsection{O delineamento das funções do princípio da boa-fé objetiva}

O princípio da boa-fé objetiva possui caráter tridimensional, que se exterioriza através de três funções elencadas no Código Civil (BRASIL, 2002), quais sejam: a interpretativa (art.113), a de controle (art.187) e a integrativa (art.422), sendo esta, a mais importante função da boa-fé objetiva, em razão de integrar qualquer relação obrigacional.

4 Nesse sentido ver: MARQUES (2006, p.217 e 218); MARTINS-COSTA (2000, p.382-409); NORONHA (2007, p.75).

5 Ver ainda: FARIAS; ROSENVALD (2006, p.40); MARTINS-COSTA (2000, p.411-412); NORONHA(1994, p.152); NORONHA (2007, p.446-447); CORDEIRO (2005, p.405); CORDEIRO (2007, p.632); MARQUES (2006, p.216) ; LÔBO (2002, p.193); NOVAIS (2001, p.22-23).

6 Nesse sentido ver também HIRONAKA (2003. p. 112-113).

Revista da Faculdade Mineira de Direito, v.14, n. 27, jan./jun. 2011 - ISSN 1808-9429. 
5.2.1. Função Interpretativa: Trata-se da forma como o intérprete vai se nortear para analisar o sentido mais correto de examinar o conteúdo contratual, pautado na observância da boa-fé nas relações jurídicas dessa sorte. Essa função impõe que o intérprete, ao analisar tais relações, não se atenha a uma interpretação literal do negócio jurídico, mas, precipuamente, guie-se por uma interpretação embasada na observância do sentido pertinente às convenções sociais inerentes àquela dada comunidade política. $O$ princípio revela-se cânone interpretativo, ou seja, referencial hermenêutico, no mesmo sentido dos paradigmas da codificação conhecidos por eticidade e socialidade.

5.2.2. Função de Controle: Visa a impor limites ao exercício abusivo do direito subjetivo dos contratantes, para determinar até onde é legítima ou não, para a obtenção do merecimento de tutela do ordenamento jurídico. A boa-fé significa a aceitação da interferência de elementos externos na intimidade da relação obrigacional, com poder limitador da autonomia contratual, pois através dela pode ser regulada a extensão e o exercício do direito subjetivo (AGUIAR JÚNIOR, 1995, p.24). Trata-se de evitar o abuso de direito, reduzindo a liberdade de atuação das partes. Isto porque determinados comportamentos, ainda que lícitos, não observam a eticidade preconizada pelo princípio da boa-fé objetiva, e assim negligenciam os ditames da lealdade, honestidade e confiança mútua, que devem orientar a conduta das partes nas relações jurídicas.

5.2.3. Função Integrativa: A boa-fé objetiva é fonte criadora de novos deveres especiais de conduta (NORONHA, 1994, p.157) a serem observados pelas partes durante o vínculo obrigacional. Desta função irradiam os chamados deveres anexos de conduta, impostos pela boa-fé objetiva (BIERWAGEN, 2003, p. 56). É a função mais importante do referido princípio, pois os deveres anexos que se originam deste passam obrigatoriamente a integrar qualquer relação obrigacional, para que esta seja equilibrada, de maneira a permitir a confiança mútua e a expectativa dos contratantes. Assim o Direito Obrigacional e, em especial, os contratos irão nortear-se pelo exercício da autonomia privada acrescida dos deveres anexos de conduta impostos pela função integrativa da boa-fé objetiva, em promoção do equilíbrio contratual. 


\subsection{Os deveres anexos de conduta}

O princípio da boa-fé objetiva criou os chamados deveres anexos de conduta (laterais, instrumentais etc), os quais se introjetam em toda relação jurídica obrigacional, para instrumentalizar o correto cumprimento da obrigação principal e a satisfação dos interesses envolvidos no contrato (NEGREIROS, 2002, p.153-154). Assim, além do dever da prestação (obrigação principal), surgem também outros deveres de conduta durante a relação jurídica (obrigação secundária) (MARTINS, 2000, p.104-105) ${ }^{7}$, os quais devem ser observados pelos contratantes, sob pena de ofensa à boa-fé objetiva.

Os deveres anexos de conduta podem ser compreendidos como deveres positivos e negativos, que, através da sua inserção na relação jurídica, por meio da boa-fé objetiva, relativizam a autonomia privada, ao estabelecer deveres de comportamento, que vinculam a ação dos contratantes, nas fases pré-contratual, contratual e pós-contratual (MELLO, 2001, p.316) ${ }^{8}$.

5.3.1. Dever anexo de proteção: Pretende proteger as partes dos riscos de danos à sua pessoa e a seu patrimônio, na constância da relação obrigacional. Significa que o envolvido deve observar a proteção, o cuidado, para com os bens e integridade da contraparte, no intuito de evitar que as partes se inflijam danos mútuos (FARIAS; ROSENVALD, 2006, p.54). Trata-se de verdadeiro dever de proteção, no aspecto moral e patrimonial, durante por toda a existência da relação obrigacional;

5.3.2. Dever anexo de cooperação: Visa a impor às partes a abstenção de condutas capazes de gerar desequilíbrio entre as prestações e também impor condutas positivas que facilitem o cumprimento da prestação obrigacional. Assim, não basta que as partes cumpram a obrigação principal. Os contratantes devem cooperar entre si para que o negócio jurídico obtenha êxito, através do correto adimplemento da prestação principal da obrigação. E nesse sentido, devem, ambos os contratantes observar o princípio constitucional da solidariedade, que permeia a consecução do princípio da boa-fé objetiva;

5.3.3. Dever anexo de informação: Impõe que uma parte tem sempre o dever de informar a outra de todas as circunstâncias (fatos) que cercam o negócio jurídico. Isto porque a vontade

7 Nesse sentido ver: COUTO E SILVA (1976, p.29-30); MARTINS-COSTA (2002, p.634); LÔBO (2005, p.76). 8 Nesse sentido ver: COUTO E SILVA (1976, p.131); NORONHA (2007, p.80).

Revista da Faculdade Mineira de Direito, v.14, n. 27, jan./jun. 2011 - ISSN 1808-9429. 
de contratar deve ser esclarecida, devidamente informada ${ }^{9}$, para permitir que a manifestação de vontade ocorra em consonância com a boa-fé objetiva. Tem-se como o mais importante desses deveres, pois a informação é fundamental para que o contratante possa ser alertado sobre fatos de que não poderia perceber por sua própria diligencia ordinária (ROSENVALD, 2005, p.109) ${ }^{10}$.

O referido dever tem por finalidade ampliar o conhecimento das partes na relação contratual, desde a fase pré-contratual até a fase pós-contratual, pois a informação é fundamental para a tomada de decisão por parte do contratante.

Devido à importância concretizada pelos deveres anexos de conduta nas relações jurídicas obrigacionais, firmou-se entendimento no sentido de que, quando se descumprem os deveres anexos de conduta, tem-se a chamada violação positiva do contrato ou adimplemento ruim (GARCIA2007, p.120) ${ }^{11}$, pois a obrigação principal é cumprida, a despeito do descumprimento dos deveres anexos (obrigação secundária).

Desta forma, é imprescindível que as partes atuem nas relações jurídicas obrigacionais firmadas com observância aos deveres anexos de conduta, que impõem, para além da obrigação jurídica principal, deveres acessórios, ao quais objetivam resguardar a legítima expectativa e a confiança mútua existentes entre as partes.

\subsection{O corolário da boa-fé objetiva: princípio da transparência}

O princípio da transparência, com previsão no artigo $4^{\circ}$ caput Código de Defesa do Consumidor (BRASIL, 1990) apresenta-se como princípio básico a ser observado nos contratos em geral e, especialmente, naqueles contratos ditos de consumo. Preconiza a maneira como a informação deve ser prestada ao consumidor no ato da contratação (qualificação da informação), que deve ser clara, ostensiva, precisa e correta, visando a sanar quaisquer dúvidas no ato da contratação e garantir o equilíbrio contratual entre as partes.

É um dos instrumentos, ao lado do dever de informação, aptos a proteger a liberdade de escolha do contratante. Alguns doutrinadores entendem que o princípio da transparência advém do princípio maior da boa-fé objetiva, ou mesmo que se trata de um reflexo ou subprincípio (RIBEIRO, 2003. p.146; SCHIER, 2006, p.49; NALIN, 2006, p.146 e 150) correlato

9 Nesse sentido ver: GODOY (2007, p.80).

10 Nesse sentido ver: SCHIER (2006, p.28); MARQUES (2006, p.772).

11 Nesse sentido ver: MARQUES (2006, p.220); SILVA (2002, p.82-105); TARTUCE (2007, p.103); CORDEIRO (2007, p.594-602); NALIN (2006, p.226); SCHREIBER (2007, p.135-138).

Revista da Faculdade Mineira de Direito, v.14, n. 27, jan./jun. 2011 - ISSN 1808-9429. 86 
ao dever de informar, qualificar a informação prestada. Para outros, a transparência é corolário da boa-fé objetiva ${ }^{12}$.

A transparência impõe clareza, ou seja, informação sobre aspectos relevantes durante as tratativas (fase pré-contratual) e, por conseguinte no ato da contratação, sob pena de haver violação do princípio da transparência, por descumprimentos aos preceitos deste princípio (MARQUES, 2006, p.715) ${ }^{13}$.

Isto porque a transparência afeta a essência do contrato, pois a informação fornecida integra o seu conteúdo, de modo a concretizar o reequilíbrio obrigacional, com vistas à consecução da igualdade material. Contudo, prática comum nos contratos, mormente nos contratos de consumo, é a inserção de cláusulas que deturpam o conteúdo contratual, pois entram em desacordo com outras e acabam por impedir o entendimento claro, preciso e transparente atinente ao contrato firmado, e, por vezes, traz, a posteriori, prejuízos indesejáveis ao contratante.

O sentido da transparência seria de qualificar a autonomia privada, através da efetiva liberdade de decisão do contratante, garantida pela transparência de informações adequadas e necessárias a realização da avença.

Destarte, o dever de informação impõe ao contratante a obrigação de descrição rigorosa do produto/serviço prestado, sobretudo naqueles casos em que, pela natureza da prestação ou pelo modo de contratar, encontra-se ínsito a presença do risco.

Nesta esteira, o princípio da transparência e o dever de informação recaem sobre todas as cláusulas contratuais, que elencam direitos e deveres das partes contratantes, e permitem deste modo, o exercício adequado de direitos subjetivos.

Portanto, o princípio da boa-fé objetiva é concretizado através do princípio da transparência nas relações negociais, vinculando a parte que possui vantagens informativas, através da imposição do dever jurídico de informação clara, precisa e ostensiva de todo o conteúdo contratual, sem subterfúgios ou possibilidades de interpretações dúbias.

\section{CONCLUSÃO}

O trabalho partiu de um problema, em busca de duas respostas. Destacou a pluralidade de certificados de formação técnica complementar médica em todo o país e a necessidade de investigar a existência de eventual diferença significativa entre as mesmas. Almejou, assim,

12 GARCIA, Leonardo de Medeiros. Direito do consumidor. 3.ed., Rio de Janeiro: Impetus, 2007, p.30; 13 Nesse sentido ver: TOMASETTI JUNIOR (1992, p.53).

Revista da Faculdade Mineira de Direito, v.14, n. 27, jan./jun. 2011 - ISSN 1808-9429. 
saber se a aludida diferença existe e, caso positivo, se seria possível atestar a existência do dever do médico em prestar informação qualificada ao paciente, acerca do processo de sua formação técnica.

Partindo do recorte metodológico da área da Dermatologia, constatou-se a que a celeuma se estabelece especialmente entre dois certificados: o de Pós-Graduação Lato Sensu em Dermatologia e o Título de Especialista em Dermatologia.

Considerando que, com freqüência, os termos de consentimento informado que são entregues aos pacientes por seus médicos sucedem prévia explicação verbal que se vale de variáveis técnico-científicas impassíveis de compreensão pelo leigo, tão importante que a compreensão prognósticos, terapêutica, complicações e utilidade de um determinado procedimento é o reconhecimento, pelo paciente, da legitimidade técnica do médico na condução informativa do processo decisório para a concessão do consentimento.

A partir da análise das regulamentações de ambas as certificações, foi possível definir Títulos de Especialista como os certificados outorgados em conformidade com o convênio da Comissão Mista de Especialidades Médicas, pela Sociedade Brasileira de Dermatologia, e concedidos, após concurso, somente aos aprovados, para atestar a realização de um longo, intenso e criterioso treinamento em serviço.

O Certificado de conclusão de Pós-Graduação Lato Sensu, por sua vez, comprova a realização de curso que almeja a promoção da educação continuada, sem a necessária pretensão de realização de treinamento em serviço. Os critérios dessa modalidade de formação são estabelecidos, autonomamente, pelas Instituições de Ensino Superior e possuem exigência de carga horária mínima de 360 (trezentos e sessenta) horas efetivas.

Ambos os certificados são válidos em todo o território nacional, para os fins aos quais se propõem. Parecem, contudo, ser dotados de objetivos distintos e, por conseguinte, asseguram formações técnicas que não guardam necessária identidade.

Em conformidade com os preceitos norteadores do princípio da boa-fé objetiva, é possível afirmar pela existência do direito do paciente à obtenção de informação qualificada acerca da formação técnica do profissional médico.

A transparência determina que parte contratante (médico) com privilégio informativo esclareça, de forma clara, precisa, ostensiva, detalhada e exaustiva, ou seja, através da qualificação da informação a ser prestada, todos os elementos que possam ser considerados pela contraparte (paciente) na decisão de consentir. 
Portanto, tendo em vista que os certificados analisados guardam divergências significativas entre si, é direito do paciente a obtenção dessa informação qualificada, sob pena de ofensa à boa-fé objetiva e de risco de invalidade do consentimento informado exarado.

\begin{abstract}
This paper studies the plurality of additional technical training certificates in medical dermatology in Brazil and the importance of the investigation about the existence of any significant difference between them. The main confusions occur between two certificates: "Certificado de Pós-Graduação Lato Sensu em Dermatologia" and "Título de Especialista em Dermatologia". Given the divergence, it was highlighted the weight of technical training in the process of weighting of scientific variables to the patient, which happens before the proper consent for treatment, in order to present a patient's right to obtain such qualified information, as a result of the normative content of the principle of objective good-faith.

Keywords: Certificates of Specialization; Dermatology; Qualified information; Objective good-faith.
\end{abstract}

\title{
REFERÊNCIAS
}

AGUIAR JÚNIOR, Ruy Rosado de. A boa-fé na relação de consumo. Revista de Direito do Consumidor, São Paulo, n.14, p. 20-27, abr./jun., 1995, p.24.

BIERWAGEN, Mônica Yoshizato. Princípios e regras de interpretação dos contratos no novo código civil. 2.ed. São Paulo: Saraiva, 2003.

BRASIL. Código Civil (2002). Lei n⿳ 10.406, de 10 de janeiro de 2002. Disponível em: <http://www.planalto.gov.br/ccivil_03/LEIS/2002/L10406.htm>. Acesso em: 25 ago. 2010.

BRASIL. Código Comercial (1850). Lei no 556, de 25 de junho de 1850. Disponível em: <http://www.planalto.gov.br/ccivil_03/Leis/L0556-1850.htm>. Acesso em: 25 ago. 2010.

BRASIL. Código de Defesa do Consumidor (1990). Lei no 8.078, de 11 de setembro de 1990. Disponível em:<http://www.planalto.gov.br/ccivil_03/Leis/L8078.htm>. Acesso em: 25 ago. 2010.

BRASIL. Conselho Federal de Medicina. Resolução CFM no 1.845, de 12 de junho de 2008. Dispõe sobre a nova redação do Anexo II da Resolução CFM n ${ }^{\circ} 1.785 / 2006$, que celebra o convênio de reconhecimento de especialidades médicas firmado entre o Conselho Federal de Medicina (CFM), a Associação Médica Brasileira (AMB) e a Comissão Nacional de Residência Médica (CNRM). Disponível em:

<http://www.portalmedico.org.br/resolucoes/cfm/2008/1845_2008.htm>. Acesso em: 25 ago. 2010 .

BRASIL. Decreto no 44.045, de 19 de julho de 1958. Aprova o Regulamento do Conselho Federal e Conselhos regionais de Medicina a que se refere a Lei $\mathrm{n}^{\circ} 3.268$, de 30 de setembro de 1957. Disponível em: <http://www.planalto.gov.br/ccivil_03/decreto/19501969/D44045.htm>. Acesso em: 25 ago. 2010.

Revista da Faculdade Mineira de Direito, v.14, n. 27, jan./jun. 2011 - ISSN 1808-9429. 
BRASIL. Decreto no 80.281, de 05 de setembro de 1977. Regulamenta a Residência Médica, cria a Comissão Nacional de Residência Médica e dá outras providências. Disponível em: <http://portal.mec.gov.br/setec/arquivos/pdf/legislacao.pdf>. Acesso em: 25 ago. 2010.

BRASIL. Lei no 3.268, de 30 de setembro de 1957. Dispõe sobre os Conselhos de Medicina, e dá outras providências. Disponível em:

<http://www.planalto.gov.br/ccivil_03/Leis/L3268.htm>. Acesso em: 25 ago. 2010.

BRASIL. Lei no 6.932, de 7 de julho de 1981. Dispõe sobre as atividades do médico residente e dá outras providências. Disponível em:

<http://www.planalto.gov.br/ccivil_03/Leis/L6932.htm>. Acesso em: 25 ago. 2010.

BRASIL. Ministério da Educação. Resolução CNE/CES nº 1, de 3 de abril de 2001. Estabelece normas para o funcionamento de cursos de pós-graduação. Disponível em: <http://portal.mec.gov.br/seed/arquivos/pdf/tvescola/leis/CES0101.pdf>. Acesso em: 25 ago. 2010.

BRASIL. Ministério da Educação. Resolução CNE/CES n¹, de 8 de julho de 2007. Estabelece normas para o funcionamento de cursos de pós-graduação lato sensu, em nível de especialização. Disponível em: 〈http://portal.mec.gov.br/cne/arquivos/pdf/rces001_07.pdf〉. Acesso em: 25 ago. 2010.

CORDEIRO, António Manuel da Rocha e Menezes. Da boa-fé no direito civil. Coimbra: Almedina, 2007.

CORDEIRO, António Manuel da Rocha e Menezes. Tratado de direito civil português: volume 1: parte geral, tomo 1: introdução doutrina geral negócio jurídico. 3. ed. aumentada e inteiramente revista Coimbra: Almedina, 2005.

COUTO E SILVA, Clóvis do. A obrigação como processo. São Paulo: José Bushatsky, 1976.

FARIAS, Cristiano Chaves de; ROSENVALD, Nelson. Direito das obrigações. Rio de Janeiro: Lumen Juris, 2006.

FIUZA, César. Direito Civil: curso completo. 9. ed. rev., atual. e ampl. Belo Horizonte: Del Rey, 2006.

GARCIA, Leonardo de Medeiros. Direito do consumidor. 3.ed., Rio de Janeiro: Impetus, 2007.

GODOY, Cláudio Luiz Bueno de. Função social do contrato: os novos princípios contratuais. 2.ed., rev. e atual. São Paulo: Saraiva, 2007.

HIRONAKA, Giselda Maria Fernandes Novaes. Tendências do Direito Civil no Século XXI. In: FIUZA, César Augusto de Castro; SÁ, Maria de Fátima Freire de; NAVES, Bruno Torquato de Oliveira (Coords.). Direito Civil: atualidades. Belo Horizonte: Del Rey, 2003, p.93-114. 
LÔBO, Paulo Luiz Netto. Princípios sociais dos contratos no Código de Defesa do

Consumidor e no novo Código Civil. Revista de Direito do Consumidor, São Paulo, v.11, n.42, p.187-195, abr./jun. 2002.

LÔBO, Paulo Luiz Netto. Teoria geral das obrigações. São Paulo: Saraiva, 2005.

MARQUES, Claudia Lima. Contratos no código de defesa do consumidor: o novo regime das relações contratuais. 5. ed. rev., atual. e ampl. São Paulo: Revista dos Tribunais, 2006.

MARTINS-COSTA, Judith. A boa-fé no direito privado: sistema e tópica no processo obrigacional. São Paulo: Revista dos Tribunais, 2000.

MARTINS-COSTA, Judith. Mercado e solidariedade social entre cosmos táxis: A boa-fé nas relações de consumo. In: MARTINS-COSTA, Judith (Org.). A reconstrução do direito privado: reflexos dos princípios, diretrizes e direitos fundamentais constitucionais no direito privado. São Paulo: Revista dos Tribunais, 2002, p.611-661.

MELLO, Heloísa Carpena Vieira de. A boa-fé como parâmetro da abusividade no direito contratual. In: TEPEDINO, Gustavo (Coord.). Problemas de Direito Civil-Constitucional, Rio de Janeiro: Renovar, 2001, p.307-324.

NALIN, Paulo. Do contrato: conceito pós-moderno em busca de sua formulação na perspectiva civil-constitucional. 2.ed., Curitiba: Juruá, 2006.

NEGREIROS, Teresa. Teoria do contrato: novos paradigmas. Rio de Janeiro: Renovar, 2002.

NORONHA, Fernando. Direito das obrigações: volume 1: fundamentos do direito das obrigações, introdução à responsabilidade civil. 2. ed. rev. e atual. São Paulo: Saraiva, 2007.

NORONHA, Fernando. O direito dos contratos e seus princípios fundamentais: autonomia privada, boa-fé e justiça contratual. São Paulo: Saraiva, 1994.

NOVAIS, Alinne Arquette Leite. Os novos paradigmas da teoria contratual: o princípio da boa-fé objetiva e o princípio da tutela do hipossuficiente. In: TEPEDINO, Gustavo (Coord.). Problemas de Direito Civil-Constitucional, Rio de Janeiro: Renovar, 2001, p.17-54.

RIBEIRO, Joaquim de Sousa. O Imperativo de Transparência no Direito Europeu dos Contratos. In: FIUZA, César Augusto de Castro; SÁ, Maria de Fátima Freire de; NAVES, Bruno Torquato de Oliveira (Coords.). Direito Civil: atualidades. Belo Horizonte: Del Rey, 2003, p.131-157.

ROSENVALD, Nelson. Dignidade humana e boa-fé no Código Civil. São Paulo: Saraiva, 2005.

SCHIER, Flora Margarida Clock. A boa-fé como pressuposto fundamental do dever de informar. Curitiba: Juruá, 2006. 
SCHREIBER, Anderson. A boa-fé objetiva e o adimplemento substancial. In: HIRONAKA, Giselda Maria Fernandes Novaes; TARTUCE, Flávio (Coords.). Direito Contratual: temas atuais. São Paulo: Método, 2007, p.125-146.

SILVA, Jorge Cesa Ferreira da. A boa-fé e a violação positiva do contrato. Rio de Janeiro: Renovar, 2002.

SOCIEDADE BRASILEIRA DE DERMATOLOGIA. Edital do XLIII exame para obtenção do título de especialista em Dermatologia. Disponível em:

<http://docs.google.com/viewer?a=v\&q=cache:wh3hBgLixNYJ:www.sbd.org.br/medicos/soc iedade/titulo/edital_2009.pdf+edital+XLIII+site:www.sbd.org.br\&hl=pt-

BR\&gl=br\&pid=bl\&srcid=ADGEESiw8WZpIVi2SZB_Kq1AZgV6A0nYWHYVAa9sP5Qeo HGHiovuwqQb7WP780nvumKpe_8HgHJqX1YGApMJdRh_ssiQp3-

WazrmCmfdq_JFou6wTuzRD_HSx6cXh7bruiIrp4rJhliX\&sig=AHIEtbQRaWSao5UWnMgwN37F_F64pQhzA>. Acesso em: 25 ago. 2010.

SOCIEDADE BRASILEIRA DE DERMATOLOGIA. Regimento para Credenciamento de Serviços, da Sociedade Brasileira de Dermatologia. Disponível em:

<http://www.sbd.org.br/down/Pdf/regimento/credenciamento.pdf>. Acesso em 25 ago. 2010.

TARTUCE, Flávio. Direito Civil. v.3: teoria geral dos contratos e contratos em espécie. 2.ed., São Paulo: Método, 2007.

TOMASETTI JUNIOR, Alcides. O objetivo de transparência e o regime jurídico dos deveres e riscos de informação nas declarações negociais para consumo. Revista de Direito do Consumidor, São Paulo, n.4, p.52-90, 1992. 